\title{
The Concept of Oncoplastic Breast Surgery Applied in Surgery for a Giant Fibroadenoma
}

\author{
Michael Rose ${ }^{1,2,3 *}$, Henry Svensson ${ }^{3,4}$ \\ ${ }^{1}$ Department of Surgery, Section of Plastic Surgery, Sydvestjysk Sygehus, Esbjerg, Denmark \\ ${ }^{2}$ Department of Plastic Surgery, Aleris-Hamlet Hospitaler, Copenhagen, Denmark \\ ${ }^{3}$ Department of Clinical Sciences in Malmö, Lund University, Lund, Sweden \\ ${ }^{4}$ Department of Plastic and Reconstructive Surgery, Skåne Univeristy Hospital, Malmö, Sweden \\ Email: "michael.rose@rsyd.dk
}

Received 28 December 2013; revised 26 January 2014; accepted 23 February 2014

Copyright (C) 2014 by authors and Scientific Research Publishing Inc.

This work is licensed under the Creative Commons Attribution International License (CC BY).

http://creativecommons.org/licenses/by/4.0/

(c) (i) Open Access

\section{Abstract}

The treatment of a 40-year-old woman with a giant fibroadenoma in her left breast is presented. The fibroadenoma measured $14 \times 5 \times 3 \mathrm{~cm}$ and weighed $170 \mathrm{~g}$. We demonstrate that the surgical strategy and the reconstructive techniques in oncoplastic breast cancer surgery successfully can be applied to the treatment of these rare benign tumours improving the cosmetic and functional outcome.

\section{Keywords}

\section{Giant Fibroadenoma, Partial Immediate Breast Reconstruction, Oncoplastic Breast Surgery}

\section{Introduction}

Fibroadenoma is a rather common nodular benign tumour of the breast [1]. A giant fibroadenoma, defined as a fibroadenoma larger than $5 \mathrm{~cm}$ or with a weight $500 \mathrm{~g}$ or more, constitutes just $0.5 \%$ - $2 \%$ of all fibroadenomas [1] [2]. The fibroadenoma is a mixed fibroepithelial benign tumor, often with a considerable cystic component, and is usually incapsuled, sometimes lobulated, and most often unilateral [1]. Fibroadenomas occur most often in younger women, but giant fibroadenomas can also occur in adolescents as a rapid growing tumour [1] [3]. The tumour often causes discomfort and anxiety of malignancy besides asymmetry to the contralateral breast for obvious reasons. Treatment is radical surgery with removal of the entire tumour. Surgery for larger fibroademo-

"Corresponding author. 
nas in the breast is challenging as removal of the tumour leaves the breast with considerable and mutilating defect as well as asymmetry to the contralateral breast.

The aim of this case report is to bring forward how the challenge of treating a large fibroadenoma can be met by applying the surgical reconstructive techniques usually used for breast cancer in oncoplastic breast surgery.

\section{Case Report}

A 40-year-old healthy woman with recurrence of a fibroadenom in the upper lateral quadrant of the left breast was referred to Privathospitalet Hamlet in 2008. The patient had had surgery 14 years earlier for a fibroadenoma located in the same position. It was apparently not removed radically primarily as the fibroadenoma continued to grow in the following years. The patients primary concern was pain and discomfort related to the tumour. Secondly, she was not pleased by the cosmetic appearance because of the resulting asymmetry to the normal right breast.

Clinical examination showed that the left breast had a huge tumour located in the upper lateral-mid-part of the breast resulting in asymmetry to the right breast with a volume difference about 200 cc (Figure 1). Mammography and ultrasound showed a multicystic fibroadenoma with no signs of malignancy. Axillary lymphnodes showed normal architecture. A pre-operative biopsy was not considered necessary.

Surgery was planned and performed with removal of the fibroadenoma en-bloc as a partial mastectomy. The incision lines were drawn as known from reduction mammaplasty (Figure 2(a)). The specimen measured approximately $14 \times 5 \times 3 \mathrm{~cm}$ and its weight was $170 \mathrm{~g}$. Hence, a considerable defect of the breast had to be handled with (Figure 2(b)). The problem was solved by means of immediate partial reconstruction with the displacement technique. Consequently, an extended superomedial deepitheliased flap wearing the nipple-areolacomplex was used and the flap was transposed to the defect in the upper lateral part of the breast (Figure 2(c)). To correct asymmetry, a mastopexy was done at the right breast. Histological examination of the specimen confirmed the diagnosis of a fibroadenoma with no sign of malignancy.

Follow-up in the outpatient unit was done after 2 weeks, 3 month and after 3 years and 4 months. No early or late postoperative complications occurred. At the latest visit the patient had no signs of recurrence of the fibroadenoma. She had no pain or discomfort from either breast and she was very pleased with the cosmetic outcome of the surgery (Figure 3).

\section{Discussion}

Surgery for larger and giant fibroadenomas of the breast is challenging as the resection of the tumour causes a considerable defect of the breast as well as an asymmetry to the contralateral breast. As the patients most often are young women it is of particular importance that the esthetical and functional outcome is the best possible. In the literature, several approaches to resection with or without reconstruction are described mostly as case-reports.

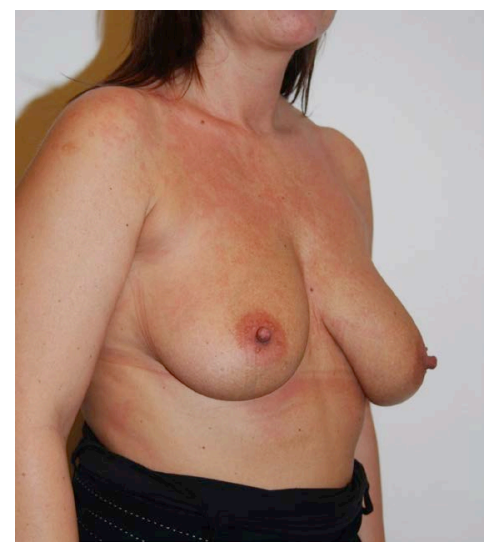

(a)

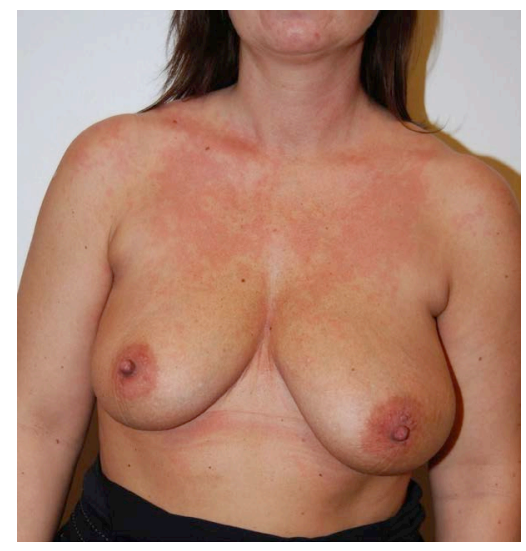

(b)

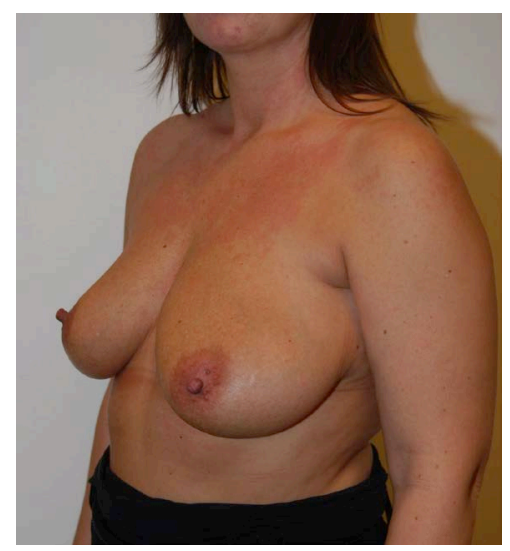

(c)

Figure 1. Preoperative photos of a 40-year women with asymmetria of the breast caused by a fibroadenoma in the upper lateral part of the left breast. 


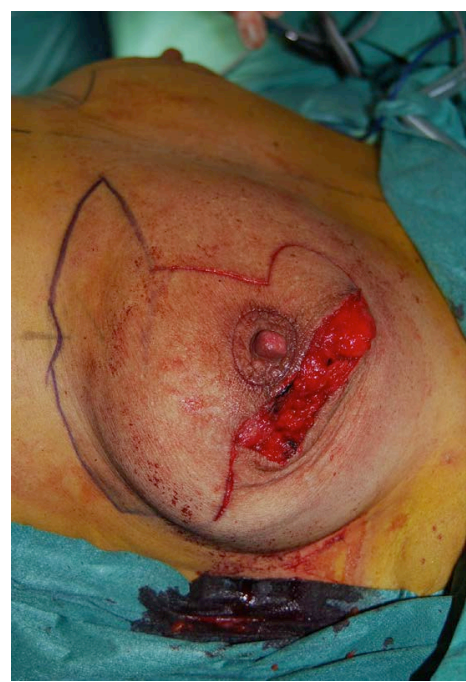

(a)

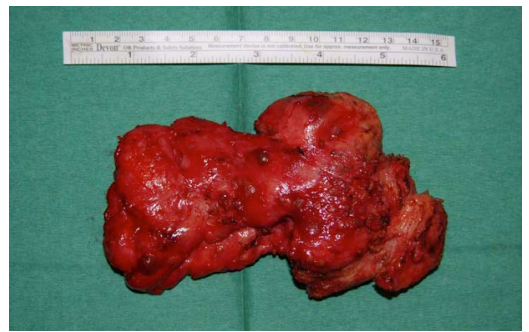

(b)

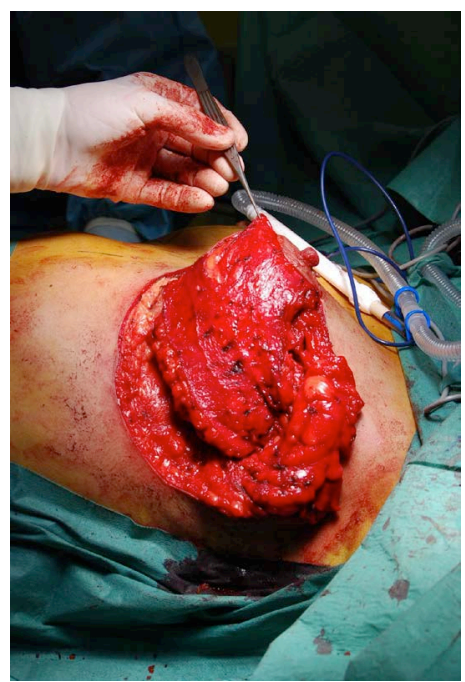

(c)

Figure 2. Peroperative photos showing incision lines and the incision through which the fibroadenoma was removed (a), the fibroadenoma measuring $14 \times 5 \times 3 \mathrm{~cm}$, weight $170 \mathrm{~g}$ (b) and the deepitheliased superomedial extended flap in position in the defect after removal of the adenoma (c).

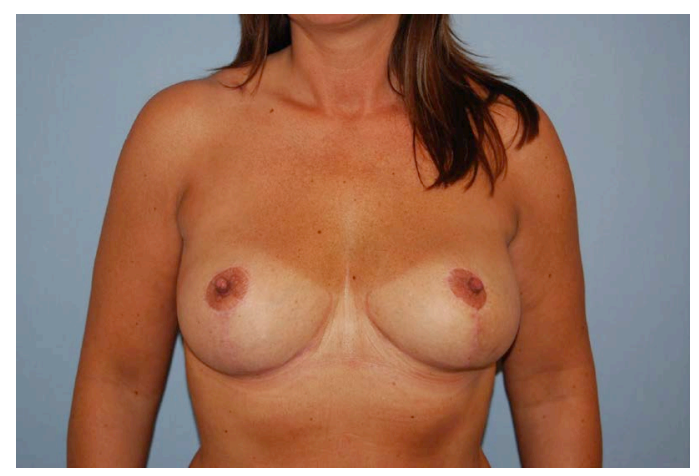

(a)

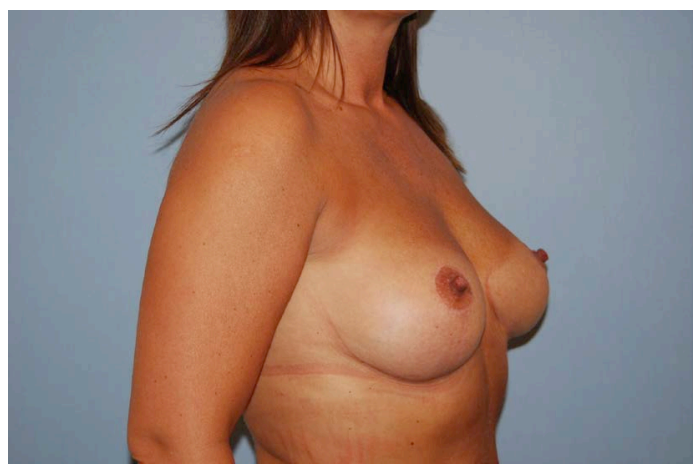

(b)

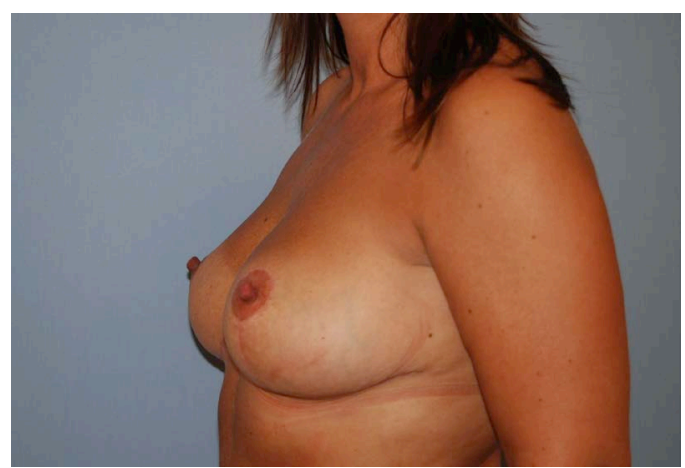

(c)

Figure 3. Postoperative photos 3-year and 4 months after surgery.

These case reports give examples of simple excision [3] [4], excision in combination with mastopexy or mamma reduction plasty [4] [5], mastectomy [2] as well as excision with immediate reconstruction with prosthesis [6]. A report by A. Nour et al. is of particular interest in this context as they report results of oncoplastic techniques in the management of giant and multiple benign lesions of the breast using the of round block and mammaplasty techniques [7]. 
In our case, we actually applied the principles for preoperative evaluation and considered the various reconstructive techniques that we regularly use in oncoplastic breast cancer surgery. In oncoplastic breast surgery three different techniques are used; volume reduction, volume displacement and volume replacement. The technique for reconstruction to be used depends on the relation between the size of the tumour, the size of the breast and the location of the tumour [8]-[10]. For our patient, we chose an immediate partial reconstruction with the volume displacement technique using an extended superomedial internal flap to fill the defect after removal of the fibroma with the chance of giving the breast a natural shape. In the same surgical procedure, we made a mastopexy on the contralateral side to achieve symmetry which also is in agreement with the concept of oncoplastic breast surgery. In other cases of large benign tumours, the techniques of volume reduction or volume replacement may be used depending on the relation between the size of the tumour, the size of the breast and the location of the tumour.

\section{Conclusion}

In summary, the concept of oncoplastic breast surgery has improved the outcome of treatment of malignant lesions, but the same concept can be applied to improve the outcome of treatment of benign lesions of the breast as well. Large benign lesions are rather rare and the purpose of this report is to bring forward the concept of oncoplastic breast surgery for these cases.

\section{Conflict of Interest}

The authors have no conflict of interest.

\section{References}

[1] Chang, D.S. and McGrath, M.M. (2007) Management of Benign Tumors of the Adolescentbreast. PRS, 120, 13-19.

[2] McCague, A. and Davis, J.V. (2010) Giant Fibroadenoma in a 22 Year Old Patient: Case Report and Literature Review. Breast Disease, 31, 49-52.

[3] Gobbi, D.P., Dall’Igna, P., Alaggio, R., Nitti, D. and Cecchetto, G. (2009) Giant Fibroadenoma of the Breast in Adolescent-Report of 2 Cases. Journal of Pediatric Surgery, 44, 39-41. http://dx.doi.org/10.1016/j.jpedsurg.2008.11.041

[4] Park, C.A., David, L.R. and Argenta, L.C. (2006) Breast Asymmetry: Presentation of a Giant Fibroadenoma. The Breast Journal, 12, 451-461. http://dx.doi.org/10.1111/j.1075-122X.2006.00303.x

[5] Chepla, K.J., Armijo, B.S., Ponsky, T.A. and Soltanian, H.T. (2011) Benefits of Immediate Dermoglandular Preserving Reconstruction Following Giant Fibroadenoma Excision in Two Patients. JPRAS, 64, 244-247.

[6] Dolmans, G.H.C.G., Hoogbergen, M.M. and van Rappard, J.H.A. (2007) Giant Fibroadenoma of One Breast: Immediate Bilateral Reconstruction. JPRAS, 60, 1156-1157.

[7] Nour, A., Gharieb, F., Tashkni, M. and Helm, T. (2011) Oncoplastic Breast Surgery for the Management of Giant and Multiple Benign Breast Lesions. European Surgery, 43, 295-301. http://dx.doi.org/10.1007/s10353-011-0021-3

[8] McCulley, S.J. and Macmillan, R.D. (2005) Planning and Use of Therapeutic Mammoplasty—Nottingham Approach. British Journal of Plastic Surgery, 58, 889-901. http://dx.doi.org/10.1016/j.bjps.2005.03.008

[9] McCulley, S.J. and Macmillan, R.D. (2005) Therapeutic Mammaplasty-Analysis of 50 Consecutive Cases. British Journal of Plastic Surgery, 58, 902-907. http://dx.doi.org/10.1016/j.bjps.2005.03.007

[10] da Silva, A.V., Destro, C. and Torres, W. (2007) Oncoplastic Surgery of the Breast: Rationale and Experience of 30 Cases. The Breast, 16, 411-419. http://dx.doi.org/10.1016/j.breast.2007.01.014 